\title{
Pyogenic Granuloma in an Atypical Location Following Isotretinoin Treatment
}

Carlos Cuenca-Barrales, Teresa Ródenas-Herranz, Laura Linares-Gonzalez, *Ricardo Ruiz-Villaverde
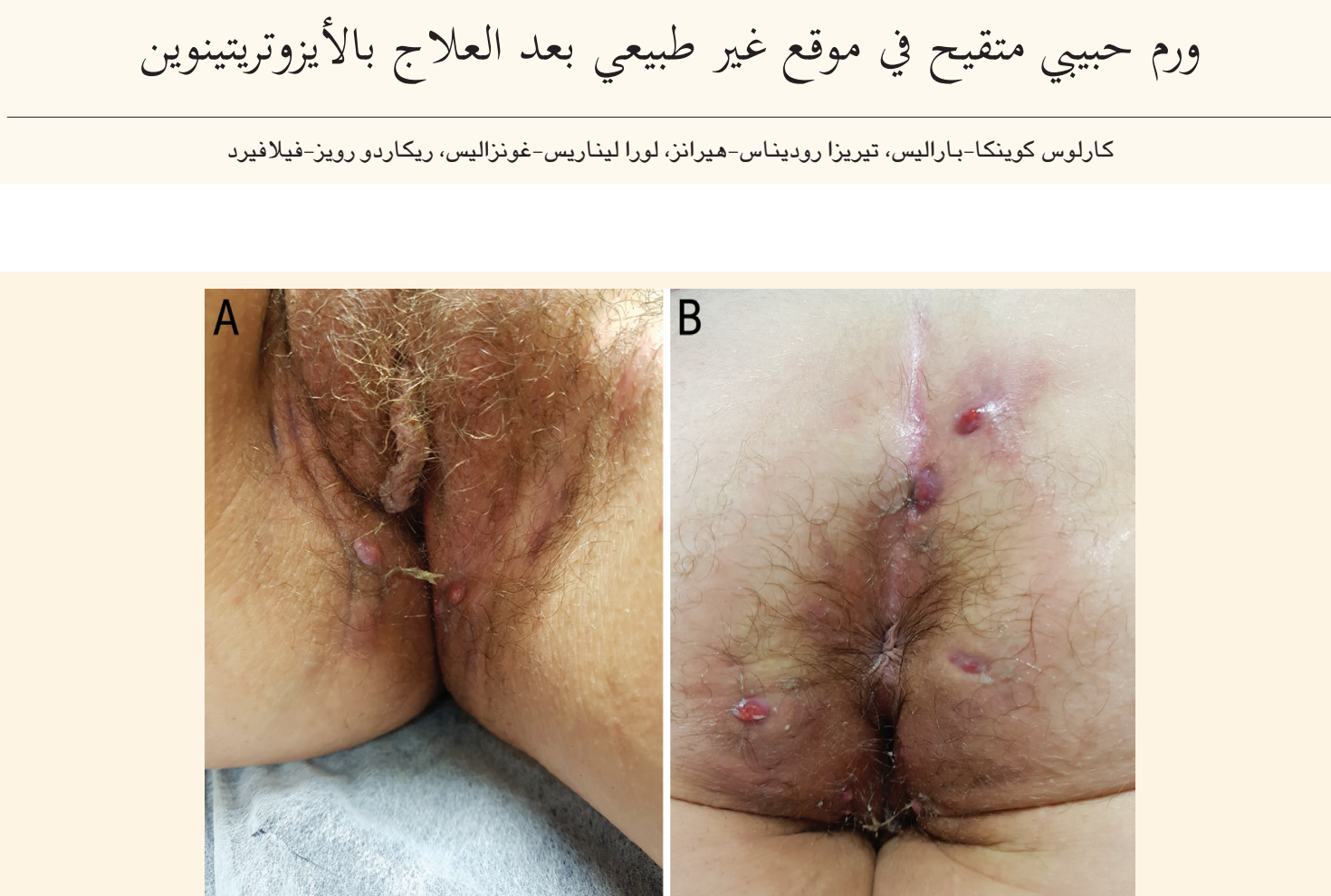

Figure 1: Clinical photographs of an 18-year-old patient with multiple ulcerated exophytic dome-shaped lesions located on the (A) inner side of both groins and (B) intergluteal fold.

A N 18-YEAR-OLD WOMAN PRESENTED TO THE outpatient dermatology clinic of the Hospital Universitario San Cecilio, Granada, Spain, in 2017 for a scheduled three-month follow-up appointment after having been prescribed $30 \mathrm{mg} /$ day of oral isotretinoin for the control of severe acne. At the follow-up appointment, she reported multiple ulcerated exophytic dome-shaped lesions prone to haemorrhage in the intergluteal fold and pubic region [Figure 1]. She had no significant past medical history and did not report ever having had hidradenitis in the affected location nor any past trauma following hair removal.

The results of complementary tests, including a complete blood count, general biochemistry tests and urinalysis, were within normal limits. A histological examination of the largest lesion was compatible with a diagnosis of pyogenic granuloma (PG) [Figure 2]. Subsequently, the isotretinoin dose was reduced to $15 \mathrm{mg} /$ day and a topical application of clobetasol propionate twice daily was administered. The patient reported the complete resolution of the lesions within three weeks.

\section{Comment}

Also known as capillary lobular haemangioma, PG is a benign vascular lesion that can compromise the skin or mucous membranes and usually occurs in children or adolescents. ${ }^{1}$ It was first described in 1979 following high doses of vitamin A. ${ }^{2}$ It has also been reported after treatment with topical and/or systemic retinoids-such as isotretinoin-between two weeks and six months after the initiation of treatment. ${ }^{3,4}$ Most cases reported in the literature are located in the periungual area (i.e. lateral and distal nail folds), although it can also affect the chest, back, face, scalp and, less frequently, the genital area, as in the present case. ${ }^{5-8}$ 


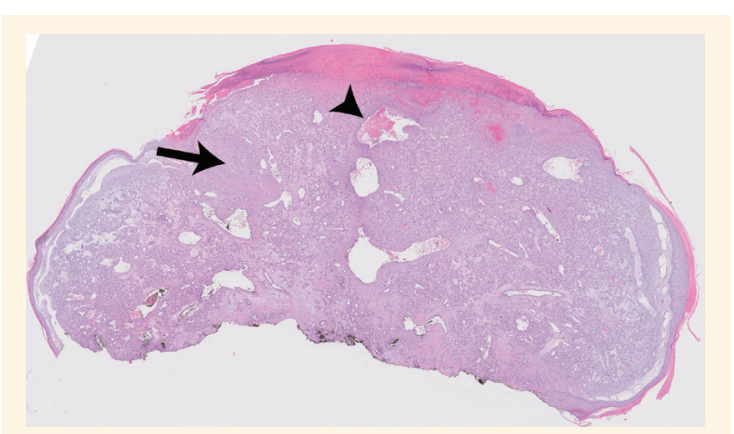

Figure 2: Haematoxylin and eosin stain at $\mathrm{x} 2$ magnification showing capillaries and venules with plump endothelial cells (arrowhead) separated into lobules by fibromyxoid stroma (arrow).

The pathophysiology of PG is still not clear. Isotretinoin may increase skin fragility and increase vascular proliferation. Alternatively, retinoids promote early stages of wound healing, cause the accumulation of mononuclear cells in the dermis and stimulate collagen synthesis, all of which may contribute to PG formation. ${ }^{3,5}$ Different triggering factors have also been postulated, including local trauma, bacterial infections and skin fragility. ${ }^{5,6}$ Such factors can lead to the formation of granulation tissue. ${ }^{9}$ Other causative factors may include the intake of other drugs, such as oral contraceptives, or pregnancy-related hormonal changes. ${ }^{10}$

From a therapeutic point of view, there is no need to discontinue isotretinoin treatment, although the dose should be modified temporarily. ${ }^{7}$ In addition, the topical application of corticosteroids and/or antibiotics is common to promote occlusive healing for 2-3 weeks. Following this, if there is no clinical response, surgical removal is recommended.

\section{References}

1. Patrice SJ, Wiss K, Mulliken JB. Pyogenic granuloma (lobular capillary hemangioma): A clinicopathologic study of 178 cases. Pediatr Dermatol 1991; 8:267-76. doi: 10.1111/j.1525-1470.19 91.tb00931.x.

2. Hagedorn M, Kirchner S. [Multiple granulomata pyogenica in a patient with acne vulgaris (author's transl)]. Dermatologica 1979; 158:93-8. doi: 10.1159/000250749.

3. Simmons BJ, Chen L, Hu S. Pyogenic granuloma association with isotretinoin treatment for acne. Australas J Dermatol 2016; 57:e144-5. doi: 10.1111/ajd.12418.

4. Figueiras Dde A, Ramos TB, Marinho AK, Bezerra MS, Cauas RC. Paronychia and granulation tissue formation during treatment with isotretinoin. An Bras Dermatol 2016; 91:223-5. doi: 10.15 90/abd1806-4841.20163817.

5. Armstrong K, Weinstein M. Pyogenic granulomas during isotretinoin therapy. J Dermatol Case Rep 2011; 5:5-7. doi: 10.3315/ jdcr.2011.1062.

6. Türel A, Oztürkcan S, Sahin MT, Türkdogan P. A rare side-effect of systemic isotretinoin treatment: Pyogenic granuloma. J Eur Acad Dermatol Venereol 2003; 17:609-11. doi: 10.1046/j.14683083.2003.00620.x.

7. Exner JH, Dahod S, Pochi PE. Pyogenic granuloma-like acne lesions during isotretinoin therapy. Arch Dermatol 1983; 119:808-11. doi: 10.1001/archderm.1983.01650340018012.

8. Gupta S, Radotra BD, Kumar B. Multiple, genital lobular capillary haemangioma (pyogenic granuloma) in a young woman: A diagnostic puzzle. Sex Transm Infect 2000; 76:51-2. doi: 10.1136/ sti.76.1.51.

9. Campbell JP, Grekin RC, Ellis CN, Matsuda-John SS, Swanson NA, Voorhees JJ. Retinoid therapy is associated with excess granulation tissue responses. J Am Acad Dermatol 1983; 9:708-13. doi: 10.1016/S0190-9622(83)70184-2.

10. Mussalli NG, Hopps RM, Johnson NW. Oral pyogenic granuloma as a complication of pregnancy and the use of hormonal contraceptives. Int J Gynaecol Obstet 1976; 14:187-91. doi: 10.10 02/j.1879-3479.1976.tb00592.x. 